ORIGINAL ARTICLE

\title{
Supervisory behaviour as a predictor of return to work in employees absent from work due to mental health problems
}

\author{
K Nieuwenhuijsen, J H A M Verbeek, A G E M de Boer, R W B Blonk, F J H van Dijk
}

Occup Environ Med 2004;61:817-823. doi: 10.1136/oem.2003.009688

\begin{abstract}
See end of article for authors' affiliations

Correspondence to:

Dr K Nieuwenhuijsen,

Coronel Institute for

Occupational and

Environmental Health,

Academic Medical Centre,

University of Amsterdam,

PO Box 22700, 1100 DD

Amsterdam, Netherlands;

K.Nieuwenhuijsen@amc.

uva.nl
\end{abstract}

Accepted 5 May 2004

\begin{abstract}
Aims: To study supervisory behaviour as a predictive factor for return to work of employees absent due to mental health problems; and to explore the association between conditional factors and supervisory behaviour.

Methods: Eighty five supervisors of employees were interviewed by telephone. Questionnaires providing information on person related factors, depressive symptoms, and sickness absence were sent to the employees at baseline, three months, six months, and after one year. Three aspects of supervisory behaviour during the period of absence were measured: communication with the employee, promoting gradual return to work, and consulting of other professionals.

Results: Better communication between supervisor and employee was associated with time to full return to work in non-depressed employees. For employees with a high level of depressive symptoms, this association could not be established. Consulting other professionals more often was associated with a longer duration of the sickness absence for both full and partial return to work. If sickness absence had financial consequences for the department, the supervisor was more likely to communicate frequently with the employee. Supervisors who were responsible for return to work in their organisation were more likely to communicate better and to consult more often with other professionals.

Conclusion: Supervisors should communicate more frequently with employees during sickness absence as well as hold follow up meetings more often as this is associated with a faster return to work in those employees.
\end{abstract}

S ickness absence is not solely determined by ill health, but is also influenced by factors such as work environment and social support. ${ }^{12}$ Consequently, regaining health does not necessarily result in return to work. In employees who are absent due to mental health problems, this notion is substantiated by the finding that symptom reduction is not always followed by work recovery. ${ }^{34}$ However, little is known of the non-medical determinants of successful return to work in employees with mental health problems.

Supervisory behaviour has been mentioned as one of these non-medical determinants of return to work. ${ }^{5-7}$ Supervisors are expected to play a key role in the return to work process, in addition to occupational health professionals or other medical professionals. Supervisors are most familiar with the requirements of the job, they are the first to communicate with workers about return to work, and they usually have the authority to implement adjustments in working conditions. Therefore, several authors have argued that supervisory behaviour is an important determinant of return to work in workers with physical injuries.

It is difficult to draw an overall conclusion on the effect of supervisory behaviour on sickness absence since different study designs, different populations, and different measures of supervisory behaviour and outcome are used. Two cross sectional studies showed that positive supervisory behaviour was associated with fewer workdays $\operatorname{lost}^{8}$ and better job accommodation in employees who had successfully returned to work. ${ }^{5}$ Even though we found no prospective studies that concerned supervisory behaviour towards employees during sickness absence, supervisory support prior to the period of absence was found to be predictive of the rate of return to work in employees with health complaints. ${ }^{9}$ In workers with mental health problems it was shown that support by the supervisor had an influence on the incidence of periods of short term sickness absence. ${ }^{10}$

Over the years, several interventions have been evaluated in which supervisors were trained to display positive supervisory behaviour. Although these training sessions were effective in enhancing positive supervisory behaviour, ${ }^{11-15}$ their effect on sickness absence was inconsistent. Wood ${ }^{15}$ showed a decrease in long term absence at the organisational level. Moreover, McLellan and colleagues ${ }^{14}$ found a reduction in sickness absence days as reported by the supervisors themselves. In contrast to these positive results, Jensen and Bodin $^{12}$ could not show a positive effect of supervisory behaviour on the return to work rates of employees on sick leave due to back pain.

In summary, evidence tentatively suggests that supervisory behaviour can influence sickness absence by influencing the non-medical aspects of absenteeism. However, the effect of supervisory behaviour and its various components on return to work of employees with mental health problems has not yet been established. Therefore, we studied supervisory behaviour as a predictive factor for return to work of employees with mental health problems, while accounting for the potential confounding effect of severity of psychological symptoms and person related factors such as age, gender, and occupation.

Conditional factors such as organisation policy or quality of the work relationship with the employee may hinder or enhance positive supervisory behaviour. For instance, a financial incentive within the organisation predicts the likelihood that supervisors will make efforts to promote return to work. ${ }^{16}$ More insight into the association between

Abbreviations: DASS, Depression Anxiety Stress Scales; HR, hazard ratio; V, Cramer's V; Cl, confidence interval 


\section{Main messages}

- No direct relation between positive supervisory behaviour and time to both full and partial return to work was observed.

- Frequent communication between supervisors and nondepressed employees on sickness absence is associated with a shorter duration of the sickness absence until full return to work.

- Supervisors communicate better and consult other professionals more frequently if the supervisor is responsible for return to work and if sick leave has financial consequences for their department.

conditional factors and supervisory behaviour may provide points of departure for future interventions. Therefore, the secondary aim of this study is to explore the association between conditional factors and supervisory behaviour.

\section{METHODS \\ Participants}

As part of a longitudinal cohort study of employees with mental health problems, we approached individual occupational physicians to participate in the study and to ask their colleagues to join them. This snowball method resulted in 30 occupational physicians from nine occupational health services who provided data on consecutive patients. Eligible employees had to be on sick leave due to mental health problems for less than six weeks. Mental health problems were defined as psychological symptoms that were reported by the employee. Employees with psychological symptoms which were caused by a somatic disorder were excluded from the study. Any previous consultation with the occupational physician had to be more than three months previously in order to select incident cases only.

Data on 277 employees were reported to us by the occupational physicians, of which $66(24 \%)$ refused to participate in the cohort study. Of the 211 eligible employees who signed an informed consent form, 198 filled out the baseline questionnaire. Of these patients, 98 gave the researchers additional consent to contact their supervisor. All 98 supervisors were approached, five of whom refused to participate. Eight supervisors could not be contacted or interviewed despite at least five attempts. In total, 85 supervisors were actually interviewed.

\section{Procedure}

The inclusion period of the study lasted from March 2001 until February 2002. All employees were monitored for one year. According to the Dutch sickness absence insurance system of that time, an employee could be sick listed for one year, after which the assessment for a permanent disability benefit would take place. Employees were sent questionnaires at baseline, and 3, 6, and 12 months. Supervisors were interviewed by telephone six months after the baseline questionnaire. A copy of the interview questions was sent to the supervisors beforehand. The duration of the interviews varied from 5 to 15 minutes.

\section{Measures}

\section{Outcome measures}

Time to full return to work was defined as the number of days between the first day of sickness absence and the first day of full return to work. Full return to work was operationalised as working the same number of hours as prior to the sickness absence. Partial return to work was the

\section{Policy implications}

- Supervisors are advised to keep in touch with employees who are on sickness absence at least once every two weeks.

- It may be desirable to make supervisors responsible for the return to work process and to ensure that sick leave has financial consequences for their departments.

secondary outcome measure of this study. Partial return to work was operationalised as a first return to work, regardless of the number of hours per week. Time to return to work could exceed 365 days due to the time between the first day of absence and the time of baseline measurement. Absence data were retrieved with each questionnaire. Moreover, at the last follow up participants were asked to give an overview of their sickness absence during the previous 12 months. If inconsistencies were discovered between that overview and their answers in earlier questionnaires or if absence data could not be retrieved from the questionnaire, the sick leave register of the occupational health service was consulted.

\section{Supervisor interview}

All data on supervisory behaviour and conditional factors were derived from a standardised telephone interview comprising 19 questions. Three aspects of supervisory behaviour were distinguished: communication with the employee, promoting a gradual return to work, and consulting with professionals such as human resource managers and psychologists. For example, one question concerning communication with the employee was: "Did you initiate contact with the employee during the period of sickness absence?" If the answer was affirmative, then the following questions were: "How often?" (more than once a week, once a week, once every two weeks, or once a month); and "How?" (by telephone, face-to-face, or by email).

To compute indicators of supervisory behaviour, the answers were classified into potentially positive and potentially negative contributions to the return to work process. For each indicator, specific criteria were formulated. See the Appendix for a detailed description of the indicators and criteria. Indicators could be assigned a l (positive supervisory behaviour) or a 0 (no positive supervisory behaviour).

In addition, we asked the supervisors six questions with regard to the following conditional factors: Does the employer charge any financial consequences of absence to supervisor's department? (yes/no); Is sufficient funding for rehabilitation purposes available? (yes/no); Is supervisor responsible for return to work? (yes/no); Was employee motivated for work prior to sickness absence? (yes/no); Was performance of employee at work satisfactory prior to sickness absence? (yes/no); Was work relationship with employee good? (yes/no).

\section{Questionnaire}

Data on patient characteristics were collected with the baseline questionnaire. The questionnaire provided information on severity of psychological symptoms, age, gender, occupation, and self reported cause of mental health problems. Severity of psychological symptoms was measured by the Depression subscale of the Depression Anxiety Stress Scales (DASS), ${ }^{17}$ because depression was shown to be more predictive of a longer duration of sickness absence than other types of mental health disorders. ${ }^{18}$ The DASS -42 consists of 42 symptoms divided into three subscales of 14 items: Depression Scale, Anxiety Scale, and Stress Scale. 
Participants rated the extent to which they had experienced each symptom over the previous week on a four point Likert scale ranging from 0 (did not apply to me at all) to 3 (applied to me very much, or most of the time). We dichotomised the Depression Scale applying the cut off score of $>12 .{ }^{19}$

We categorised occupation into three groups: mentally demanding work, a combination of mentally and physically demanding work, and physically demanding work. ${ }^{20}$ Branches of industry were classified according to the NACE nomenclature. ${ }^{21}$ The cause of the mental health problems was assessed by one item: "What do you perceive to be the cause of your sickness absence?" Possible answers were high workload, conflicts with supervisor or colleagues, and personal circumstances. If none of these answers applied, patients could specify another cause for their sickness absence. The answers to this question were dichotomised into work related (solely work related or work related in combination with another cause) and not work related.

\section{Statistical analysis}

First, we calculated the percentage of supervisors who met our criteria for positive supervisory behaviour. Next, we examined the multivariate associations between supervisory behaviour and time to both partial and full return to work by using Cox's regression analysis. The three indices of supervisory behaviour were related to outcome in three separate analyses. At the first stage of these analyses, the influence of one component of supervisory behaviour on time to return to work was examined. Subsequently, the proportional hazard assumption was tested for all three components of supervisory behaviour separately. Therefore, an interaction term of time, defined as before or after a point in time, with supervisory behaviour was added to the equations. The cut off point for time was determined after a visual inspection of the log minus log graph.

At the second step of the analyses, all three models were checked for the confounding influence of severity of depressive symptoms, age, gender, occupation, and self reported cause of mental health problems. These possible confounders were added to the models one by one. If a change in hazard ratio (HR) for supervisory behaviour of more than $10 \%$ was observed, the variable was identified as a confounder and included in the multivariate model. In the third step, the interaction term of severity of depressive symptoms and supervisory behaviour was added to the models to examine the modifying effect of depressive symptoms.

Finally, in order to address our second research aim, we described associations between conditional factors and supervisory behaviour by means of calculating Cramer's V. This measure of association was used because both conditional factors and supervisory behaviour were dichotomous variables. The value ranges between 0 and 1 , with 0 indicating no association between the row and column variables and values close to 1 indicating a high degree of association between the variables.

Analyses were performed using the SPSS, version 10.0.7, software package (SPSS Inc., Illinois, USA).

\section{RESULTS}

\section{Employees}

Table 1 presents the employee characteristics at baseline. A non-response analysis including time to return to work, severity of depressive symptoms, age, gender, occupation, and cause of mental health problems revealed no statistically significant or relevant differences between employees who did or did not give permission to contact their supervisor. We were unable to retrieve the sickness absence data of four employees whose supervisors were interviewed. Time to return to work ranged from 7 to 476 days with a median of 91

\section{Table 1 Employee characteristics at baseline}

\begin{tabular}{ll}
\hline Employee characteristic & \\
\hline Gender, \% male & 42 \\
Age, mean (SD) & 44.2 (8.6) \\
Description of occupation, \% & 46 \\
Mentally demanding (light and heavy) & 50 \\
Combination of mentally and physically demanding & 4 \\
Physically demanding (light and heavy) & \\
Type of occupation, \% & 63 \\
Education & 11 \\
Public administration & 10 \\
Real estate, renting and business activities & 8 \\
Transport, storage and communication & 5 \\
Health and social work & 2 \\
Manufacturing & 1 \\
Wholesale and retail & 68 \\
Cause of mental health problems, \% work related & 58 \\
Severity of depressive symptoms, \% DASS-D >12 & \\
\hline \multirow{2}{*}{ Due to missing values, $\mathrm{n}$ is 83 or 84.} &
\end{tabular}

days for partial and 215 days for full return to work. At the end of follow up, 18 (22\%) employees had not fully returned to work but 17 of these had partially returned to work.

\section{Supervisory behaviour}

Table 2 displays the frequencies of positive supervisory behaviour.

\section{Communication with employee}

A majority of the supervisors (72\%) contacted their employees at least once every two weeks. Most supervisors (89\%) had organised a follow up meeting after the employee had first returned to work or partially returned to work. In 55 cases $(65 \%)$ the supervisor satisfied both criteria.

\section{Promoting gradual return to work}

In only a minority of the cases was the explicit discussion of a return to work plan a substantial feature of the contacts between supervisor and employee (14\%). Supervisors stimulated return to work before complete recovery of symptoms in only 22 cases $(26 \%)$. This was mainly due to the belief that employees should be free of symptoms in order to return to work. Our criteria for work accommodation were met in 53 cases $(62 \%)$. In $68 \%$ of these 53 cases, modifications in the number of working hours were carried through, while work content was modified in $61 \%$ of the cases.

\section{Consulting with professionals}

Most supervisors $(79 \%)$ consulted occupational physicians regarding return to work of their employees. Other professionals were consulted slightly more often $(82 \%)$.

\section{Relation between supervisory behaviour and outcome} Table 3 presents the results of the Cox's regression analyses. Since Cox's regression is a survival analysis, hazard ratios indicate the hazard of dying whereas in our case the event is return to work. Therefore, a hazard ratio smaller than one indicates a risk of a longer time to return to work. The first step revealed no main effects of supervisory behaviour on full return to work in any of the three models. Furthermore, the proportional hazards assumption was not violated in any of the three supervisory behaviours. The second step indicated that the addition of confounders did not account for more than a $10 \%$ change in the HR in any of the models. To examine the interaction of severity of depressive symptoms and supervisory behaviour, severity of depressive symptoms was also added to the model in step three.

According to the Wald statistic, the interaction term introduced in step three was statistically significant 
Table 2 Frequency of positive supervisory behaviour $(n=85)$

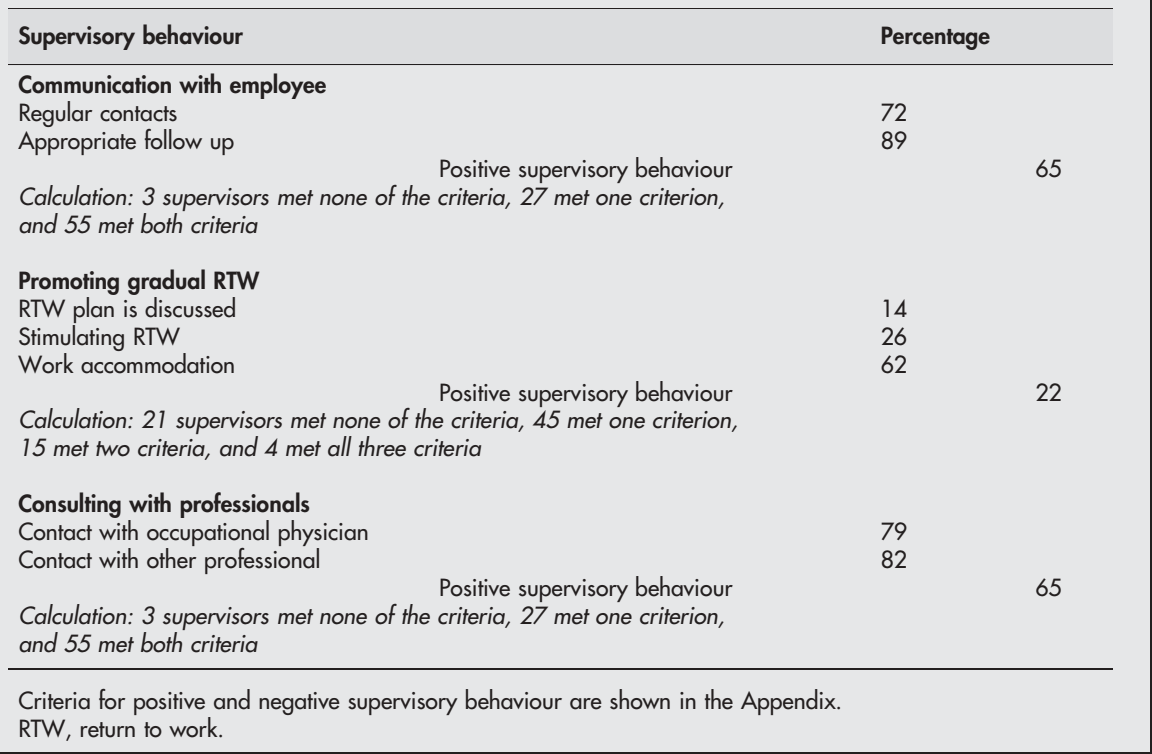

$(\mathrm{p}<0.05)$ for communication with the employee. The HR for communication with the employee was 3.5 (95\% CI 1.4 to 8.9) for employees with DASS-D scores lower than 12, which corresponds to a median of 341 days in the group with positive supervisory behaviour compared to 118 days in the other group. For employees with higher DASS-D scores, the analysis revealed an HR of 1.6 (95\% CI 0.8 to 3.2, not in table, calculated from model), which corresponds with a median of 280 days in the group with positive supervisory behaviour compared to 223 days in the other group. The interaction term was neither statistically significant for promoting return to work nor for consulting with professionals. However, the addition of the interaction term for consulting with professionals did yield statistically significant main effects of both consulting with professionals and severity of depressive symptoms. The HR for consulting with professionals was 0.4 (95\% CI 0.2 to 0.9$)$ for all employees.

For a partial return to work, the first step also revealed no main effects of supervisory behaviour on duration of absence in any of the three models. As with full return to work, the second step indicated that the addition of confounders did not account for more than a $10 \%$ change in the HR in any of the models of partial return to work. The interaction term introduced in step three was statistically significant $(\mathrm{p}<0.05)$ for the model with consulting with professionals. The HR for consulting with professionals was 0.4 (95\% CI 0.2 to 0.8 ) for employees with DASS-D scores lower than 12. For employees with higher DASS-D scores, the analysis revealed

Table 3 Cox's regression of relation between independent variables and time to partial $(n=80)$ and full $(n=81)$ return to work

\begin{tabular}{|c|c|c|c|c|c|c|}
\hline & \multicolumn{2}{|c|}{ Stepl } & \multicolumn{2}{|c|}{ Step 2} & \multicolumn{2}{|c|}{ Step 3} \\
\hline & HR & $(95 \% \mathrm{Cl})$ & HR & $(95 \% \mathrm{Cl})$ & HR & $(95 \% \mathrm{Cl})$ \\
\hline \multicolumn{7}{|l|}{ Full return to work } \\
\hline \multicolumn{7}{|l|}{ Communication with employee } \\
\hline Communication with employee & 1.6 & (0.9 to 2.7$)$ & 1.7 & $(1.0$ to 2.8$)$ & 3.5 & (1.4 to 8.9 ) \\
\hline Depressive symptoms & & & 0.6 & $(0.4$ to 1.0$)$ & 1.5 & (0.6 to 3.8$)$ \\
\hline Communication $\times$ depressive & & & & & 0.3 & $(0.1$ to 0.9$)$ \\
\hline \multicolumn{7}{|l|}{ Promoting return to work } \\
\hline Promoting return to work & 0.7 & (0.4 to 1.4$)$ & 0.8 & $(0.4$ to 1.5$)$ & 1.1 & (0.4 to 2.8$)$ \\
\hline Depressive symptoms & & & 0.6 & $(0.4$ to 1.1$)$ & 0.7 & $(0.4$ to 1.2$)$ \\
\hline Promoting return to work $\times$ depressive & & & & & 0.6 & $(0.2$ to 2.2$)$ \\
\hline \multicolumn{7}{|l|}{ Consulting with professionals } \\
\hline Consulting with professionals & 0.6 & $(0.4$ to 1.0$)$ & 0.6 & $(0.4$ to 1.0$)$ & 0.4 & $(0.2$ to 0.9$)$ \\
\hline Depressive symptoms & & & 0.6 & $(0.4$ to 1.0$)$ & 0.4 & $(0.2$ to 0.9$)$ \\
\hline Consulting $\times$ depressive & & & & & 2.0 & $(0.7$ to 5.6$)$ \\
\hline \multicolumn{7}{|l|}{ Partial return to work } \\
\hline \multicolumn{7}{|l|}{ Communication with employee } \\
\hline Communication with employee & 1.3 & $(0.7$ to 2.0$)$ & 1.3 & $(0.8$ to 2.0$)$ & 1.7 & $(0.8$ to 3.5$)$ \\
\hline Depressive symptoms & & & 0.6 & $(0.4$ to 1.0$)$ & 0.8 & (0.4 to 1.8$)$ \\
\hline Communication $\times$ depressive & & & & & 0.6 & $(0.2$ to 1.6$)$ \\
\hline \multicolumn{7}{|l|}{ Promoting return to work } \\
\hline Promoting return to work & 0.9 & $(0.5$ to 1.5$)$ & 0.9 & $(0.5$ to 1.5$)$ & 0.7 & (0.3 to 1.8$)$ \\
\hline Depressive symptoms & & & 0.6 & $(0.4$ to 1.0$)$ & 0.6 & $(0.4$ to 1.0$)$ \\
\hline Promoting return to work $x$ depressive & & & & & 1.3 & $(0.4$ to 4.0$)$ \\
\hline \multicolumn{7}{|l|}{ Consulting with professionals } \\
\hline Consulting with professionals & 0.8 & $(0.5$ to 1.3$)$ & 0.7 & $(0.5$ to 1.2$)$ & 0.4 & $(0.2$ to 0.8$)$ \\
\hline Depressive symptoms & & & 0.6 & $(0.4$ to 0.9$)$ & 0.3 & $(0.1$ to 0.6$)$ \\
\hline Consulting $\times$ depressive & & & & & 2.8 & (1.1 to 7.2 ) \\
\hline
\end{tabular}


an HR of 0.3 (95\% CI 0.1 to 0.7 , not in table, calculated from model).

\section{Conditional factors}

Table 4 displays the frequencies of conditional factors and the associations with supervisory behaviour. Financial consequences are charged to the supervisor's department in $42 \%$ of the cases. This was associated $(\mathrm{V}=0.28)$ with positive supervisory behaviour with regard to communication with the employee. In $71 \%$ of the organisations, the supervisor was responsible for the return to work process. The occupational physician was considered responsible by the supervisor in $20 \%$ of the cases. Responsibility of supervisor was associated with positive supervisory behaviour regarding both communication with the employee $(\mathrm{V}=0.31)$ and consulting with professionals $(\mathrm{V}=0.29)$. None of the other conditional factors were significantly associated with supervisory behaviour.

\section{DISCUSSION}

We found that better communication between supervisor and employee is associated with favourable full return to work rates in non-depressed employees. For employees with a high level of depressive symptoms, this association could not be established. Contrary to our expectations, promoting gradual return to work was not related to time to partial and full return to work. Furthermore, we found a relation between consulting with other professionals and return to work which was contrary to our expectations. Consulting other professionals more often was associated with a longer duration of the sickness absence for both full and partial return to work. Supervisors communicated better and consulted other professionals more frequently if the supervisor was responsible for return to work and if sickness absence involved financial consequences for their department.

Our measure of supervisory behaviour was fairly comprehensive, covering three domains of supervisory behaviour that were mentioned as being important for return to work in the literature. Furthermore, in this study we could relate supervisory behaviour to return to work at the level of the individual employee since we interviewed the supervisor of each participant. Finally, our follow up period was long enough to for most employees to have completely returned to work by the end of follow up.

Three methodological features of this study should be taken into account when assessing our findings. The first methodological consideration points to the generalisability of the research findings. The cohort study consisted mainly of employees from both the education and the services sector. Since occupational physicians always take care of specific companies or organisations, none of them will tend a population which is representative of the whole working population. We therefore chose to create a relatively homogeneous cohort by including employees from problematic sectors. The education sector was chosen because common mental disorders are of particular concern within the teaching profession. ${ }^{22}$ Yet, when generalising to other populations, one should take into consideration the specific characteristics of our cohort, for instance the large proportion of employees with medium or higher educational levels. Furthermore, only $48 \%$ of the participants in the cohort study gave permission to contact their supervisor, which made this study susceptible to selection bias. We postulated that employees with problematic relationships with their supervisors would be most likely to decline. However, our nonresponse analysis revealed no differences with regard to the work relatedness (including conflicts) of the mental health problem.

The second methodological consideration concerns the risk of recall bias. We interviewed the supervisors six months after baseline. A substantial proportion of the employees had already returned to work by that time, which may have introduced recall bias. Consequently, supervisors may have been influenced by outcome. Even though the supervisors were unaware of our criteria for positive supervisory behaviour, this could have led to a distorted picture of their efforts. It is, however, difficult to tell if this would have led to an over- or underestimation of the relation between supervisory behaviour and full return to work. The validity of sickness absence data has been questioned because of the possibility of recall bias if employees are retrospectively queried about their sickness absence. ${ }^{24} 25$ In a study that compared self report measures with sick leave registers, it was found that the longer the recall period was, the greater was the inaccuracy of the estimate of number of days absent due to sickness. ${ }^{25}$ Recall bias led to non-systematic inaccuracies if the recall period was 6-12 months. Our recall period during the one year follow up was twice in three months and only once in six months. Moreover, at the last follow up participants were asked to give an overview of their sickness absence during the previous 12 months. If inconsistencies were discovered between that overview and their answers in earlier questionnaires, the sick leave register of the occupational health service was consulted. Thus, the use of data from self report of sickness absence is considered justifiable.

The third methodological reflection concerns the risk of confounding. It should be appreciated that sickness absence is not solely determined by a health condition, but is a composite outcome comprising health, social, working, and personal conditions. ${ }^{12}$ In this study, we were able to check for the confounding influence of severity of depressive symptoms, age, gender, occupation, and self reported cause of mental health problems. We cannot exclude that other factors, such as the size of the workplace or the duration of the employment, have confounded the relation between supervisory behaviour and return to work. However, it should be noted that adjustment for too many variables may constitute over-control and thereby lead to an underestimation of the associations, because such factors may also be part of the causal pathway.

Table 4 Conditional factors: percentages and associations (Cramer's V) with supervisory behaviour $(n=85)$

\begin{tabular}{|c|c|c|c|c|}
\hline \multirow[b]{2}{*}{ Conditional factor } & \multirow[b]{2}{*}{$\%$ affirmative } & \multicolumn{3}{|c|}{ Association with supervisory behaviour } \\
\hline & & Communication & Promoting RTW & Consulting \\
\hline Financial consequences charged? & 42 & $0.28^{*}$ & 0.13 & 0.17 \\
\hline Sufficient funding? & 64 & 0.15 & 0.13 & 0.12 \\
\hline Supervisor responsible for return to work? & 71 & $0.31^{*}$ & 0.18 & $0.29^{*}$ \\
\hline Employee motivated for work? & 57 & 0.17 & 0.01 & 0.12 \\
\hline Work performance employee satisfactory? & 70 & 0.02 & 0.15 & 0.16 \\
\hline Work relationship with employee good? $†$ & 98 & - & - & - \\
\hline
\end{tabular}


The finding that frequent communication with the employee is associated with favourable outcome is in line with Wood ${ }^{15}$ and McLellan and colleagues, ${ }^{14}$ who advocated frequent communication in their training of supervisors. These results also correspond with earlier studies in which frequent consultations with the occupational physician were predictive of time to return to work in employees with adjustment disorders ${ }^{26}$ or back pain, ${ }^{27}$ and cancer survivors. ${ }^{28}$ The causal pathway of these findings remains unclear. Frequent contacts may elicit positive effects in the employee and may be perceived as social support, which in turn may accelerate return to work. In contrast, employees who lose contact with their supervisor or occupational physician may be especially problematical, which may account for the association found in observational studies. The observed relation between consulting with other professionals and return to work may be explained in the same way. Supervisors may consult other professionals sooner if they foresee problems in the return to work process, regardless of severity of depressive symptoms. The interaction with severity of depressive symptoms shows that the association with a later partial return to work is more pronounced in employees with higher levels of depressive symptoms.

The interaction between severity of depressive symptoms and communication with the employee suggests that the potentially favourable effect of communication was less clear in employees with high depression scores. This interaction can be interpreted in two ways. Firstly, sickness absence behaviour may be more determined by medical factors in employees with high levels of depressive symptoms compared to employees with less depressive symptoms. Since supervisory behaviour can only be expected to influence nonmedical factors, this might explain the lack of supervisor influence on return to work of depressed employees. Secondly, employees with a high level of depressive symptoms may be more difficult to communicate with. According to interpersonal theories of depression, depressed individuals evoke negative responses from others more frequently. ${ }^{29}$ Hence, the nature of the communication between employee and supervisor may have been less beneficial in employees with high levels of depressive symptoms, regardless of the frequency of contacts.

From a practical point of view, these findings suggest that supervisors should take more advantage of the role of social support by frequent communication. For non-depressed employees this may enhance return to work, while it is not associated with higher levels of depressive symptoms.

The relation between being responsible, personally and/or financially, and frequent communication supports our idea that organisational factors are important for supervisory behaviour. However, the relation between supervisory behaviour and conditional factors that we found were relatively weak. This suggests that conditional factors are not absolute prerequisites for positive supervisory behaviour.

Moreover, the relation between supervisory behaviour and return to work seems to be more complex than we had hypothesised. Even though the results of our study do not directly support our hypothesis, we think that it would be worthwhile to organise a randomised study where supervisors are trained in managing return to work problems. That would make it possible to make more definite inferences about the influence of their behaviour on return to work. Our findings that there is an interaction with depressive symptoms should be taken into account. Furthermore, such a study could investigate the relation between the efforts of an employer and the wishes of the employee with regard to regular contacts.

In conclusion, our study shows some support for the hypothesis that supervisory behaviour is related to a shorter time to return to work in employees with mental health problems. Our advice to supervisors would be to keep in touch with employees who are sick listed at least once every two weeks.

\section{ACKNOWLEDGEMENTS}

Grants were obtained from: The Netherlands Organization for Scientific Research (NWO): Netherlands Concerted Research Action "Fatigue at Work"; Foundation for Replacement and Occupational Health in Education (Stichting Vf/BGZ)

\section{Authors' affiliations}

K Nieuwenhuijsen, J H A M Verbeek, A G E M de Boer, F J H van Dijk, Coronel Institute for Occupational and Environmental Health, Academic Medical Centre, AmCOGG, University of Amsterdam, Netherlands

R W B Blonk, TNO Work and Employment, Hoofddorp, Netherlands

\section{APPENDIX: SUPERVISORY BEHAVIOUR CRITERIA FOR INDICATORS OF SUPERVISORY BEHAVIOUR}

(1) Criteria for positive supervisory behaviour regarding communication with employee

I. Supervisor should contact employee at least once every two weeks either by telephone or face-to-face.

II. Supervisor should have follow up meeting with employee after first return to work or partial return to work of employee.

(2) Criteria for positive supervisory behaviour regarding promoting gradual return to work

I. Return to work is discussed explicitly during contacts between supervisor and employee.

II. Supervisor stimulates the employee to (partially or wholly) return to work before he or she is completely recovered.

III. Modifications in both work content and work schedule are provided. These modifications may be either temporary or permanent.

(3) Criteria for positive supervisory behaviour regarding consulting with other professionals

I. Supervisor consults occupational physician regarding return to work of employee.

II. Supervisor consults other professionals (e.g. human resource manager, community health care providers).

\section{REFERENCES}

1 Kristensen TS. Sickness absence and work strain among Danish slaughterhouse workers: an analysis of absence from work regarded as coping behaviour. Soc Sci Med 1991;32:15-27.

2 Rael EG, Stansfeld SA, Shipley M, et al. Sickness absence in the Whitehall II study, London: the role of social support and material problems. J Epidemiol Community Health 1995:49:474-81.

3 Mintz J, Mintz LI, Arruda MJ, et al. Treatments of depression and the functional capacity to work. Arch Gen Psychiat 1992;49:761-8.

4 Van Der Klink JJ, Blonk RW, Schene AH, et al. Reducing long term sickness absence by an activating intervention in adjustment disorders: a cluster randomised controlled design. Occup Environ Med 2003;60:429-37.

5 Gates LB. The role of the supervisor in successful adjustment to work with a disabling condition: issues for disability policy and practice. J Occup Rehabil 1993;3:179-90.

6 Kushnir T, Luria O. Supervisors' attitudes toward return to work after myocardial infarction or coronary artery bypass graft. J Occup Environ Med 2002;44:331-7.

7 Linton SJ. The manager's role in employees' successful return to work following back injury. Work Stress 1991;5:189-95.

8 Habeck RV, Hunt HA, VanTol B. Workplace factors associated with preventing and managing work disability. Rehabil Couns Bull 1998;42:98-143.

9 Janssen N, van den Heuvel WP, Beurskens AJ, et al. The Demand-ControlSupport model as a predictor of return to work. Int J Rehabil Res 2003;26: 1-9. 
10 Stansfeld SA, Rael EG, Head J, et al. Social support and psychiatric sickness absence: a prospective study of British civil servants. Psychol Med 1997;27:35-48.

11 Haldorsen EMH, Jensen IB, Linton SJ, et al. Training work supervisors for reintegration of employees treated for musculoskeletal pain. J Occup Rehabil 1997; 7:33-43

12 Jensen IB, Bodin L. Multimodal cognitive-behavioural treatment for workers with chronic spinal pain: a matched cohort study with an 18-month follow-up. Pain 1998:76:35-44.

13 Linton SJ. A behavioral workshop for training immediate supervisors: the key to neck and back injuries? Percept Mot Skills 1991;73:1159-70.

14 McLellan RK, Pransky G, Shaw WS. Disability management training for supervisors: a pilot intervention program. J Occup Rehabil 2001;11:33-41.

15 Wood DJ. Design and evaluation of a back injury prevention program within a geriatric hospital. Spine 1987;12:77-82.

16 Salkever DS, Shinogle J, Purushothaman M. Employers' disability management activities: descriptors and an exploratory test of the financial incentives hypothesis. J Occup Rehabil 2000;10:199-214.

17 Lovibond SH, Lovibond PF. Manual for the Depression Anxiety Stress Scales (DASS). University of New South Wales, 1993.

18 Dewa CS, Goering P, Lin E, et al. Depression-related short-term disability in an employed population. J Occup Environ Med 2002;44:628-33.

19 Nieuwenhuiisen K, De Boer AG, Verbeek JH, et al. The Depression Anxiety Stress Scales (DASS): detecting anxiety disorder and depression in employees absent from work because of mental health problems. Occup Environ Med 2003;60(suppl 1):177-82.
20 De Zwart BCH, Broersen JPJ, Van der Beek AJ, et al. Occupational classification according to work demands: an evaluation study. Int J Occup Med Environ Health 1997; 10:283-95.

21 European Union. Nomenclature générale des activités économiques dans les communautés européennes (NACE). Brussels: EU, 1990.

22 Weber A, Weltle D, Lederer P. [Illness related early pensioning of high school teachers]. Versicherungsmedizin 2002;54:75-83.

23 Young AE, Russell J. Demographic, psychometric, and case progression information as predictors of return-to-work in teachers undergoing occupational rehabilitation. J Occup Rehabil 1995;5:219-34.

24 Raphael K. Recall bias: a proposal for assessment and control. Int J Epidemiol 1987; 16:167-70.

25 Severens JL, Mulder J, Laheij RJ, et al. Precision and accuracy in measuring absence from work as a basis for calculating productivity costs in the Netherlands. Soc Sci Med 2000;51:243-9.

26 Nieuwenhuijsen K, Verbeek JH, Siemerink JC, et al. Quality of rehabilitation among workers with adjustment disorders according to practice guidelines; a retrospective cohort study. Occup Environ Med 2003;60(suppl 1):121-5.

27 Weide WE vd, Verbeek JHAM, Dijk FJH v, et al. The development and evaluation of a quality assessment instrument for occupational physicians. Occup Environ Med 1998;55:375-82.

28 Verbeek J, Spelten E, Kammeijer M, et al. Return to work of cancer survivors: a prospective cohort study into the quality of rehabilitation by occupational physicians. Occup Environ Med 2003;60:352.

29 Bieling PJ, Alden LE. Sociotropy, autonomy, and the interpersonal model of depression: an integration. Cognitive Ther Res 2001;25:167-84.

\section{$\mathrm{ECHO}$}

\section{Workers in eastern coffeehouses suffer effects of ETS}

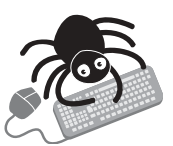

Please visit the Occupational and

Environmental Medicine website [www. occenvmed. com] for a link to the full text of this article.
$\mathrm{R}$ esearchers in Turkey have called for a ban on smoking in public places to be extended to coffeehouses, after their study showed a raised occupational risk of airway disease among workers there. This is the first study of its kind in the East, with wide ranging implications for countries where coffeehouses are part of the fabric of society, especially among unemployed and lower middle socioeconomic groups.

Coffeehouse workers-all men-were over five times more likely to have airway disease on the basis of symptoms, clinical findings, and lung function tests than other male workers in small shops nearby when confounding factors had been corrected for. The link was robust despite the high rate of smoking among both groups (86\% and $76 \%$, respectively). Comparing only smokers and correcting for pack years of smoking reduced the risk only slightly (odds ratio 4.99), showing that working in coffeehouses with their crowded, smoky atmosphere is an independent risk for airway disease. The two groups were broadly similar in mean years worked and time worked each week. Shopworkers worked in smaller premises, but their customers did not spend hours there smoking.

The cross sectional study drew on workers from three metropolitan districts of Izmir, 114 workers from 76 coffeehouses and 93 workers from 80 small shops with no known occupational risk factor for lung disease.

Data to support the likely damaging effects of environmental tobacco smoke were needed because eastern coffeehouses are different from western bars and restaurants, where previous research has been done.

A Fidan F, et al. Tobacco Control 2004;13:161-166. 